Effect of Xylitol with various concentration

Indonesian Journal of Dentistry 2009; 16 (1):72-76

http//www.fkg.ui.edu

Fakultas Kedokteran Gigi

Universitas Indonesia

ISSN 1693-9697

\title{
EFFECT OF XYLITOL WITH VARIOUS CONCENTRATION AND DURATION ON THE GROWTH OF CANDIDA ALBICANS (IN VITRO STUDY)
}

\author{
Lakshmi A. Leepel, * Shandy Sastra, ** Ria Puspitawati, ** Boy M. Bachtiar \\ *Department of Oral Biology, Faculty of Dentistry, Universitas Indonesia \\ **University student of Faculty of Dentistry, Universitas Indonesia
}

\begin{abstract}
The growth of C. albicans is influenced by glucose intake. Xylitol is commonly used as sugar substitute. Reported effective concentrations of xylitol in reducing C. albicans growth in vitro were varied, $1 \%, 5 \%$, and $10 \%$. Objectives: Investigate the effect of different concentration and duration of xylitol exposure in inhibiting C. albicans growth in vitro. Method: Identification of C. albicans from oral swab of a male candidiasis patient was conducted using CHROMagar, confirmed by germ tube test. C. albicans suspension $\left(10^{8}\right.$ cells $\left./ \mu \mathrm{l}\right)$ were inoculated in SDB contained $1 \%, 5 \%, 10 \%$ xylitol, and without xylitol (as control), for 3 and 7 days, then incubated in $37^{\circ} \mathrm{C}$ on SDA and counted for their CFU after 48 hours. The C. albicans ATCC 10231 strain was used as a comparison. Results: After 3 days, increased concentration of xylitol (1\%,5\%, 10\%) lead to decrease growth of C. albicans, both the ATCC 10231 (125\%; 51\%; 14\% respectively) and the clinical isolate $(103 \% ; 81 \% ; 42 \%), p=0.044$. Significant lower growth of C. albicans compared to control were only seen in those exposed to $10 \%$ xylitol $(\mathrm{p}=0.024)$. After 7 days, exposure of $1 \%$, $5 \%, 10 \%$ xylitol did not significantly affect the growth of $C$. albicans $(p=0.396)$. Conclusion: The growth of $C$. albicans could be inhibited by $10 \%$ xylitol for 3 days.
\end{abstract}

Key words: C. albicans; xylitol

\section{Introduction}

Candidiasis is the most common fungal infection of human and mostly caused by Candida albicans. ${ }^{1,2,3}$ In the last two decades, infection cases due to Candida species has increased significantly. ${ }^{4}$ C. albicans is indigenous to the oral cavity, gastrointestinal tract, female genital tract and sometimes the skin; hence infection is usually endogenous, although cross-infection may occur, e.g. from mother to infant, and among infant siblings. ${ }^{5}$ In oral cavity, the main oral site where it is most often found is the tongue, particularly in the posterior dorsum area in the region of the circumvallate papillae. $^{6}$

As commensal organisms and part of an individual's normal microflora, Candida species 
can be detected in approximately $50 \%$ of the population. $^{7}$ However, if the balance of the normal flora is disrupted or the immune defenses are compromised, Candida species often become pathogenic. ${ }^{7,8}$

Dietary intake of the host is one predisposing factor required for the development of Candida infection. Carbohydrate-rich diet and vitamin-deficiencies are well regarded as the vital predisposing factors of this infection. ${ }^{9,10}$ In vitro studies showed that glucose intake is a determinant promoter of C. albicans growth. ${ }^{10,11}$ In contrary to this finding, in vivo studies showed that chewing xylitol gum could decrease the adherence of $C$. albicans to buccal epithelial cells $^{12}$ and the risk of candidiasis and angular cheilitis. $^{13}$

Xylitol, a natural sweetener, can be found in foods as berries, fruit, vegetables and mushrooms. It is even generated by the human body during metabolism. Xylitol is a polyol sweetener, a sugar alcohol. It differs from other sweeteners such as sorbitol, fructose and glucose because the xylitol molecule has five, instead of six carbon atoms. ${ }^{14}$ Xylitol has $40 \%$ less calories and $75 \%$ less carbohydrates than sugar and is slowly absorbed and metabolized. ${ }^{15}$ Different from intense artificial sweeteners, including aspartame, acesulfame-K, and sucralose, xylitol has no adverse effects or bitter aftertaste. ${ }^{16}$

Compared to other polyols, xylitol has been reported to be effective in inhibiting $C$. albicans, a serious systemic yeast problem, and other harmful intestine bacteria including Helicobacter pylori, implicated in periodontal disease, bad breath, gastric and duodenal ulcers, and even stomach cancer. ${ }^{15}$ The inhibiting effect of xylitol on the Candida growth is known as dose dependent. Previous different studies reported various effective concentrations of xylitol, $1 \%,{ }^{17} 5 \%,{ }^{11} 10 \%{ }^{18}$ in reducing the growth of C. albicans in vitro. Besides that, it was known that optimum duration for the growth of C. albicans is 3 days. ${ }^{19}$

Therefore, the objectives of this study were to investigate the inhibiting effect of those various concentrations $(1 \%, 5 \%, 10 \%)$ and durations ( 3 and 7 days) of xylitol exposure on C. albicans growth in vitro.

\section{Materials and methods}

This laboratory experiment was conducted in the Oral Biology laboratory, Faculty of Dentistry, Universitas Indonesia. The laboratoric strain ATCC 10231 (American Type Culture Cell) which was taken from Microbiology Department, Faculty of Medical, Universitas Indonesia, was used as a comparison. The clinical isolate was taken from a male oral candidiasis patient who came to Oral Medicine Department, RSCM, Jakarta and received chemo-radiation therapy for his nasopharyngeal cancer.

The clinical yeast sample was taken with swab technique, and inoculated in CHROMagar. CHROMagar is a media conveniently used to identify different Candida species accurately through its pigmentation. ${ }^{20}$ After 2 days, C. albicans could be identified as pale green colonies. Confirmation of $C$. albicans was conducted by examining the formation of germ tube after incubation in Fetal Bovine Serum (FBS) for 2 hours at $37^{\circ} \mathrm{C}$. The ATCC 10231 strain and the clinical C. albicans isolate then were inoculated in Sabouraud Dextrose Agar (SDA) for 2 days.

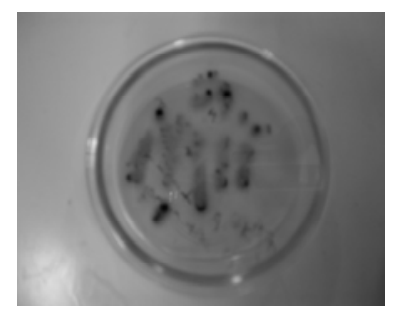

Figure 1. C. albicans identified as

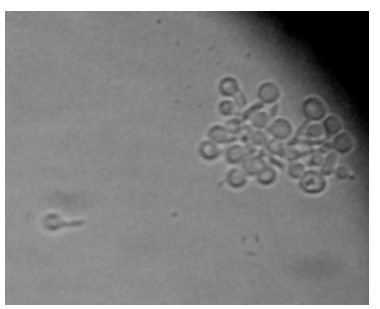

Figure 2. Germ tube formation pale green colonies in CHROMagar of C. albicans 
The inoculation were serially diluted, then inoculated in SDA for 2 days at $37^{\circ} \mathrm{C}$, and counted to get the initial Colony Forming Unit (CFU) which is the CFU from cultures before exposed to xylitol. This score was to be compared to the CFU of those exposed to xylitol after 3 or 7 days and thus the percentage of $C$. albicans growth could be analyzed.

Xylitol exposure to the $C$. albicans suspension was conducted after several stages of serial dilution, from which $10 \mu \mathrm{l}$ was taken and inoculated in $990 \mu 1$ solution of Sabouraud Dextrose Broth (SDB) containing 1\%, 5\%, or $10 \%$ xylitol, and without xylitol as control and each kept for 3 or 7 days.

After 3 days and 7 days, these inoculations were washed in PhosphateBuffered Saline (PBS) and purified by centrifugation at 10,000 rpm for 2 minutes. The CFU of C. albicans in SDA were counted after 2 days. Data was analyzed using General Linear Model (GLM) Univariat with $\alpha 0.05$.

\section{Results}

Before exposed to xylitol, the mean results of extrapolation that have been achieved from C. albicans clinical isolate was $9 \times 10^{8}$ $\mathrm{CFU} / \mathrm{ml}$ and from the ATCC 10231 strain was $1,5 \times 10^{8} \mathrm{CFU} / \mathrm{ml}$. This score will be compared to the CFU of those exposed to xylitol with various concentrations $(1 \%, 5 \%, 10 \%)$ and different duration ( 3 or 7 days) to get the percentage of C. albicans growth. To be able to compare the growth of different groups of $C$. albicans colonies (those exposed \& not exposed to xylitol), the CFU difference between those two groups was considered as $100 \%$.

For example, the control C. albicans colony after 3 days was $970 \times 10^{8} \mathrm{CFU} / \mathrm{ml}$, while the initial $\mathrm{CFU}$ was $9 \times 10^{8} \mathrm{CFU} / \mathrm{ml}$. Thus, the range between those two groups above is $970 \times 10^{8} \mathrm{CFU} / \mathrm{ml}-9 \times 10^{8} \mathrm{CFU} / \mathrm{ml}=$ $961 \times 10^{8} \mathrm{CFU} / \mathrm{ml}$. This score was considered as $100 \%$ (Table 1). For C. albicans colony exposed to $1 \%$ xylitol for 3 days, the score was $1000 \times 10^{8} \mathrm{CFU} / \mathrm{ml}$. Thus the $\mathrm{CFU}$ range compared to colony control group for 3 days was $1000 \times 10^{8} \mathrm{CFU} / \mathrm{ml}-970 \times 10^{8} \mathrm{CFU} / \mathrm{ml}=$ $30 \times 10^{8} \mathrm{CFU} / \mathrm{ml}$. This increase was considered as $\left(30 \times 10^{8} \mathrm{CFU} / \mathrm{ml}: 970 \times 10^{8} \mathrm{CFU} / \mathrm{ml}\right) \mathrm{x}$ $100 \%=3 \%$. Thus, the percentage for $C$. albicans exposed to $1 \%$ xylitol for 3 days is 103\% (Table 1).

Table 1. Percentage of C. albicans (clinical isolate and ATCC 10231) growth after exposed to xylitol $(1 \%, 5 \%$, and $10 \%)$ for 3 days and 7 days

\begin{tabular}{|c|c|r|r|r|}
\hline \multirow{2}{*}{ Medium } & \multicolumn{2}{|c|}{ C. albicans strain ATCC } & \multicolumn{2}{c|}{ C. albicans clinical } \\
\cline { 2 - 5 } & 3 days & 7 days & 3 days & 7 days \\
\hline SDB (as control) & $100 \%$ & $100 \%$ & $100 \%$ & $100 \%$ \\
\hline SDB + xylitol 1\% & $125 \%$ & $86 \%$ & $103 \%$ & $46 \%$ \\
\hline SDB + xylitol $5 \%$ & $51 \%$ & $94 \%$ & $81 \%$ & $157 \%$ \\
\hline SDB + xylitol 10\% & $14 \%$ & $73 \%$ & $42 \%$ & $94 \%$ \\
\hline
\end{tabular}

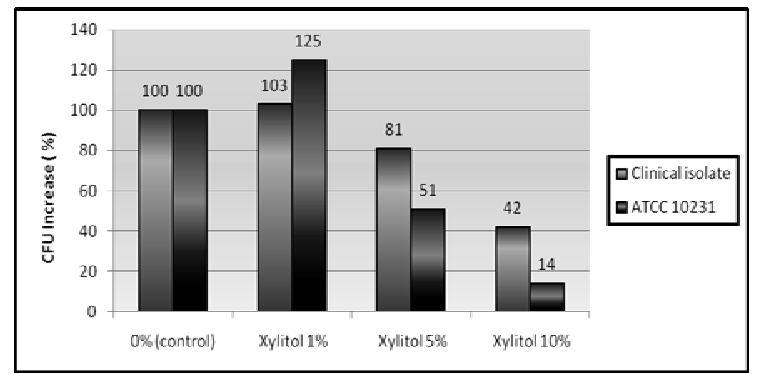

Figure 3. C. albicans Growth after Exposed to Xylitol for 3 Days 
From figure 3, it can be seen that after 3 days, the increased concentration of xylitol lead to significant decline of $C$. albicans growth $(\mathrm{p}=$ 0.044). Significant lower growth of $C$. albicans compared to control $(\mathrm{p}=0.024)$ was showed by those exposed to $10 \%$ xylitol.

Different from the results of xylitol exposure for 3 days, this study showed that the inhibitor effect of xylitol to C. albicans growth was not effective anymore after 7 days $(\mathrm{p}=$ $0.396)$.

\section{Discussion}

After 72 hours, 1\% xylitol lead to increased growth of C. albicans, both in clinical isolate and ATCC 10231, compared to control (Figure 3). However, this difference was not statistically significant. This result differs from Lee's (2004) previous study. ${ }^{17}$ No statement about the duration of xylitol exposure to $C$. albicans in Lee's study. This study was designed to analyze the effect of 3 day xylitol exposure because it is known that optimal growth of C. albicans in-vitro is 72 hours. ${ }^{19}$

Three day exposure of 5\% xylitol lead to decreased growth of C. albicans. Although such decrease of $C$. albicans growth was not statistically significant but the trend is in line with previous in vitro study from Makinen (1975). Makinen was comparing the growth of C. albicans exposed by xylitol 5\%, xylitol 5\%+ glucose $0,2 \%$, and glucose $0,2 \%$. The result of his study was that $5 \%$ xylitol could inhibit the growth of C. albicans after 72 hours.$^{11}$

In this study, 3 day exposure of $10 \%$ xylitol lead to significant declined of $C$. albicans growth. This result is in line with previous study by Munita et.al (2002). ${ }^{18}$
Although in this study the growth of $C$. albicans could only be significantly inhibitted by $10 \%$ xylitol for 3 days but the result showed that increased concentration of xylitol lead to significant decreased growth of $C$. albicans. Xylitol has 5 carbon atoms which is shorter than other sugars (glucose and fructose). ${ }^{21}$ Such different structure might be the reason for the inability of pathogenic bacteria to digest xylitol $^{22}$ and the slower absorption of this sugar through human intestine wall. $^{23}$ Higher concentration of xylitol in the media of $C$. albicans as conducted in this study, might lead to increased difficulty in absorbing sufficient nutrient required to maintain the viability of the yeast.

Conversely, after 7 days, exposure of $1 \%$, $5 \%, 10 \%$ xylitol did not significantly affect the growth of C. albicans. Different results of the effect of xylitol on the growth of C. albicans between those exposed for 3 days and those exposed to 7 days as shown in this study, might be due to the age of SDB media that influenced the medium acidity $(\mathrm{pH})$. Further research about the effect of duration to SDB properties, xylitol, and C. albicans are needed to clarify this phenomenon.

The results of this study also showed that the effect of xylitol on the growth of C. albicans is influenced by the strain of the yeast. Different phenotype between strains might contribute in those different effects of xylitol. It is likely that the more virulent clinical C. albicans is more responsive to xylitol or serum exposure, compared to the less virulent ${ }^{24}$ ATCC $10231 C$. albicans. Further research is required to investigate the role of different biologic and physiologic characters between different strains of C. albicans on their response to xylitol.

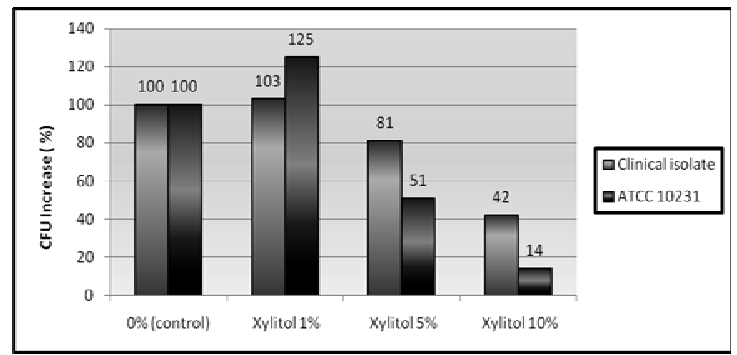

Figure 4. C. albicans Growth after Exposed to Xylitol for 7 Days 


\section{Conclusion}

Increased concentration of xylitol after 3 days significantly inhibits $C$. albicans growth in vitro. The effective concentration of xylitol to inhibit the growth of C. albicans is $10 \%$ for 3 days.

\section{References}

1. Walter JB, Grundy MC. Walter. Hamilton and Israel's principles of pathology for dental students. $5^{\text {th }}$ ed. Edinburgh: Churchill Livingstone; 1992. p. 126, 175-7.

2. Suprihatin SD. Candida dan candidiasis pada manusia. Jakarta: FKUI; 1982.

p. 3-19, 25-32.

3. Ridhawati. Mengenal jamur Candida spp sebagai penyebab keputihan. Kumpulan Makalah Ilmiah Bagian Parasitologi FK UI. 1994: 195-202.

4. Pfaller, MA. Epidemiology of candidiasis. J Hosp Infect. 1995; 30(6): 329-38.

5. Samaranayake LP. Essential microbiology for dentistry. $2^{\text {nd }}$ ed. United Kingdom: Churchill Livingstone; 2002. p. 144.

6. Marsh PD, Martin MV. Oral Microbiology. $4^{\text {th }}$ ed. London: Wright; 1999. p. 153-4.

7. Naglik JR, Challacombe SJ, Hube B. Candida albicans secreted aspartyl proteinases in virulence and pathogenesis. Microb Mol Bio Rev. 2003; 67(3): 400-28.

8. Naglik JR, Newport G, White TC. In vivo analysis of secreted aspartyl proteinase expression in human oral candidiasis. Infect. Immun. 1999; 67(5): 2482-90.

9. Waltimo TMT, Sen BH, Meurman JH, Orstavik D, Haapsalo MPP. Yeasts in apical periodontitis. Crit Rev Oral Biol Med. 2003; 14(2): 128-37.

10. Vargas SL, Patrick CC, Ayers GD, Hughes WT. Modulating effect of dietary carbohydrate supplementation on Candida neutropenic mouse model. Infect. Immun. 1993; 61(2): 61926.

11. Makinen KK, Ojanotko A, Vidgren H. Effect of xylitol on the growth of three oral strain of Candida albicans. J Dent Res. 1975; 54(6): 1239.
12. Abu-Elteen KH. The influence of dietary carbohydrates on in vitro adherence of four Candida species to human buccal epithelial cells. J Microbial Ecology in Health and Disease. 2005; 17(3): 156-62.

13. Beebe SN. The expanding utility of xylitol. Dimension of Dental Hygiene. 2006; 4(10): 34 7.

14. What is xylitol. Available from: http://www.xylitol.com/eng/index.php?page $=\mathrm{a} 7$ f8ac0455c24dd4aadb9a8080a84da.

15. Sellman S. Xylitol: our sweet salvation? The Spectrum. 2003; 4(8): p. 23.

16. Sweetlife Australia Pty Ltd. FAQ's. 2004. Available from: http://www.sweetlife.com.au/faq.htm\#4.

17. Lee HY. Inhibitor effect of sugar alcohols and chitosan on oral pathogens. IADR/AADR/CADR $82^{\text {nd }}$ General Session. 2004.

18. Munita SLV, Pearson J. The use of polyols in combating yeast infection and polyol preparation for said use. 2002. Available from: http://www.patentstrom.us/patents/6414035description.html.

19. Hoerl BG, Bryan GH. Basic medical microbiology. $3^{\text {rd }}$ ed. Boston: Little, Brown and Co; 1986. p. 777-87.

20. Yücesoy M, Marol S. Performance of CHROMagar Candida and BIGGY agar for identification of yeast species. Annals Clin Microbiol Antimicrob. 2003; 2(8).

21. Xylitol and your teeth. (download 10 Nov 2008). Available from: http://www.xylitol.com/eng/

22. Gutwosky S. Magic of xylitol. 2004 (download 19 Nov 2008). Available from: http://www.shirleygutkowskirdh.com/0304mag icofxylitol.pdf

23. Makinen KK. History, safety, and dental properties of xylitol. (download 19 Nov 2008). Available from: http://www.sweetlife.com.au/faq.htm\#4

24. Dromer F, Chevalier R, Sendid B, Improvisi L, Jouault T, Robert R, et al. Synthetic analogues of $\beta-1,2$ oligomannosides prevent intestinal colonization by the pathogenic yeast Candida albicans. Antimicrob Agents Chemother. 2002; 46(12): p. 3869-76. 